1930: Margherita Sarfatti entre Buenos Aires, Roma y Milán 1930: Margherita Sarfatti entre Buenos Aires, Roma e Milão

Dra. Laura Moure Cecchini

Como citar:

MOURE CECCHINI, L. 1930: Margherita Sarfatti entre Buenos Aires, Roma y Milán. MODOS. Revista de História da Arte. Campinas, v. 4, n. 1, p.205-223, jan. 2020. Disponível em: <https://www.publionline. iar.unicamp.br/index.php/mod/article/view/4523>.

DOI: https://doi.org/10.24978/mod.v4i1.4523.

Imagem: Margherita Sarfatti, Foto con dedicatoria al periódico ítaloargentino II Mattino d'Italia, Julio de 1930, publicada en "II '900 Italiano' a Buenos Aires", II mattino d'Italia (Buenos Aires, 21 Agosto de 1930). 


\title{
1930: Margherita Sarfatti entre Buenos Aires, Roma y Milán
}

1930: Margherita Sarfatti entre Buenos Aires, Roma e Milão

\author{
Dra. Laura Moure Cecchini*
}

\section{Resumen}

Entre el 14 de septiembre y el 4 de octubre de 1930 se exhibió una muestra de arte italiano de entreguerras en el espacio "Amigos del Arte" de Buenos Aires. Organizada por una de las más importantes críticas de arte fascistas italianas, Margherita Sarfatti y por miembros importantes de la comunidad ítalo-argentina, la exposición borró deliberadamente la línea entre "italiano" y "fascista". Analizando la intrincada curaduría transatlántica de esta exposición, y sus inversiones intelectuales en Italia y Argentina, este artículo destaca el impacto de los proyectos transnacionales en la redefinición de las geografías artísticas, al mismo tiempo que aborda el impacto del nacionalismo en la práctica del arte y la historia del arte.

\section{Palabras claves}

Arte fascista. Amigos del Arte. Margherita Sarfatti. Diplomacia cultural. Restauración del orden. Modernismo reaccionario.

\begin{abstract}
Between September 14 and October 4 1930, an exhibition of Italian interwar art was on view in Buenos Aires "Amigos del Arte" space. Organized by one of the most important Italian fascist art critics, Margherita Sarfatti and by prominent members of the Italian-Argentine community, the exhibition purposefully blurred the line between "Italian" and "fascist." Analyzing the intricate transatlantic curatorship of this show, and its intellectual investments in Italy and Argentina, this article highlights the impact of transnational projects in the redefinition of artistic geographies, while at the same time addressing the impact of nationalism on art practice and art history.
\end{abstract}

\section{Keywords}

Fascist art. Amigos del Arte. Margherita Sarfatti. Cultural Diplomacy. Return-to-Order. Modernismo reaccionario. 
El 14 de septiembre de 1930 la crítica de arte y fascista italiana Margherita Sarfatti inauguró en la asociación Amigos del Arte, en la bonaerense Calle Florida, una exposición de pintura italiana del periodo de entre guerras (Mostra del Novecento italiano, 1930). La muestra, a la que asistieron representantes de la misión diplomática italiana y miembros de las élites culturales y económicas argentinas, fue clausurada el 4 de octubre de ese mismo año. Aunque la exposición debía haberse inaugurado el 9, el golpe militar del 6 de septiembre de 1930 obligó a posponer el vernissage. Sarfatti no solamente co-organizó la exposición sino que también visitó la Argentina hasta el 20 de septiembre. Viajó a Rosario, a donde dio una conferencia en la asociación Dante Alighieri. El 16 de septiembre, siempre en Amigos del Arte, Sarfatti presentó sus ideas sobre arte del siglo XX ante un público de más de 1000 personas. Cuando dejó la Argentina el 20 de septiembre Sarfatti pasó unos días en Montevideo. Su conferencia allí tuvo tal éxito que la comunidad italiana local sugirió que una versión reducida de la muestra de Amigos del Arte también se exhibiera en la Galería Scarabello de la capital uruguaya (Corriere della Sera, Diciembre 30, 1930: 1).

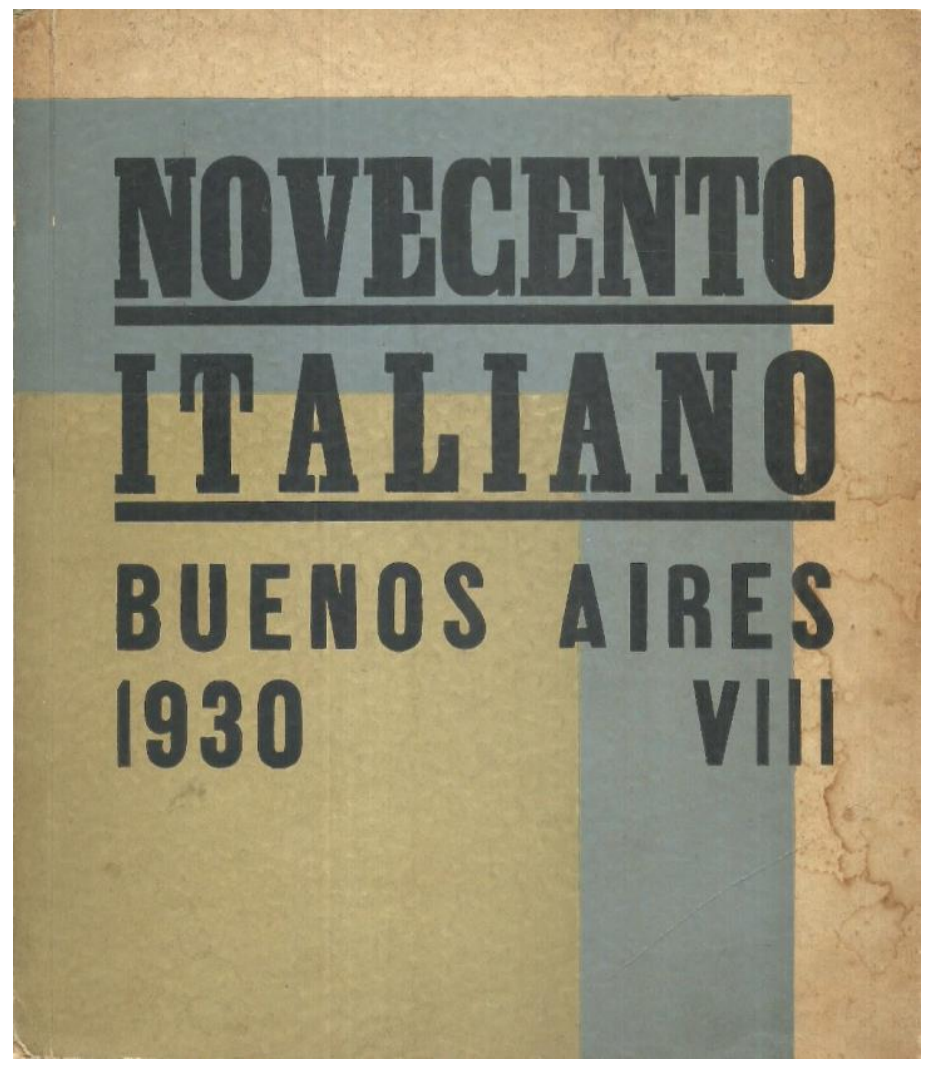

Fig.1. Detalle de la portada del catálogo da Mostra del Novecento Italiano a Buenos Aires (Buenos Aires: Amigos del Arte, 1930). Arquivo da Autora.

El movimiento Novecento italiano [Siglo XX italiano], lanzado oficialmente en 1926, fue una expresión de la tendencia artística entre guerras que giraba en torno a la "restauración del orden" (Bossaglia, 1995; Braun, 2000; Pontiggia, 2008)1.Este movimiento cultural paneuropeo fue alimentado por la 
migración de artistas y las redes intelectuales transnacionales; demandaba la interrupción de la experimentación propia de las vanguardias y movilizó el legado de la tradición para revitalizar las técnicas y los temas del arte contemporáneo. El Novecento italiano sugería un retorno a una tradición nacional supuestamente auténtica que pasaba por alto el impresionismo francés. Aunque incluía a más de cien artistas con estéticas muy diferentes, el Novecento italiano fue presentado como un esfuerzo colectivo encaminado a recuperar un enfoque clásico, atemporal, italianísimo, del arte. Las resonancias fascistas de esta propuesta se hacen evidentes al observar la portada del catálogo de la muestra de Buenos Aires, en la que el número romano VIII indica la fecha equivalente a 1930 en el calendario fascista. Fue la única vez en que una exhibición organizada directamente por Margherita Sarfatti viajó al continente americano.

Amigos del Arte era una asociación privada (patrocinada por las élites económicas y sociales locales) que abrió sus puertas a conservadores y radicales, artistas jóvenes y consolidados, argentinos y extranjeros (Mao Laos, 2007; Artundo, 2008). En lugar de centrarse en el impacto que la muestra del Novecento provocó artistas argentinos, asunto que ya ha sido investigado (Wechsler, 2003; Bastos Kern, 2017; Gonçalves Magalhães, 2018) este trabajo hablará de la exposición misma y de su turbulenta organización, centrándose en particular sobre el rol que en ella tuvo Margherita Sarfatti. Aunque Sarfatti no fue la única organizadora de la muestra - que fue el resultado de una verdadera colaboración transatlántica - sí fue la responsable de su altísima calidad, insistiendo a que se mandasen a Buenos Aires sólo obras de reconocido valor. Sarfatti emigró a Sudamérica después de que las leyes raciales italianas fueran implementadas en 1938; para continuar trabajando como crítica de arte durante su exilio y para fomentar las relaciones culturales entre Italia, Uruguay y Argentina utilizó las relaciones intelectuales que había establecido en 1930 (Gonçalves Magalhães, 2017; 2018).

¿Cuál fue la razón para exhibir la pintura neoclasicista italiana al otro lado del Atlántico? ¿Cómo se veía a la producción artística fascista italiana desde el sur? ¿Y cómo esta exposición desafió las difusas categorías del "arte italiano" y el "arte fascista" en el período de entreguerras? Mi investigación sobre esta compleja muestra y las consecuencias que tuvo para el fascismo en Italia y Argentina continúa. Como punto de partida, este artículo explorará la tortuosa génesis de la exhibición en Argentina y en Italia, y lo que esta revela sobre el intercambio cultural y artístico transatlántico a finales de los años veinte.

\section{Margherita Sarfatti y la estética fascista}

Sarfatti, una judía secular y socialista en su juventud, había sido una fascista comprometida desde los inicios del movimiento (Marzorati, 1990; Cannistraro, 1993; Urso, 2003; Barisioni, 2018). Fue amiga intima y consejera de Benito Mussolini, y una de las primeras de su entorno en reconocer la importancia política del arte en la Italia fascista.

Sarfatti fue la crítica de arte y figura intelectual femenina más importante de la primera década del régimen, desde la Marcha sobre Roma de 1922 hasta mediados de los años 30, cuando cayó en desgracia y fue sistemáticamente marginada hasta que tuvo que dejar Italia. Debido a la indiferencia general hacia el campo artístico entre los ideólogos fascistas en los primeros años del régimen, Sarfatti fue capaz de dictar directrices clave para la estética fascista. De hecho, estudiosos como Philip Cannistraro, Laura Malvano, Ruth Ben Ghiat y Emilio Gentile, entre otros, han señalado que en los 
primeros años del régimen no había ninguna política estética o cultural generada directamente por Mussolini u otros oficiales fascistas. Sarfatti, a pesar de no ostentar un cargo oficial dentro del Estado o del partido, tenía una carrera y un prestigio personal suficientemente consolidados que le permitieron impulsar a los artistas que defendía como la élite cultural del nuevo Estado (Urso, 2003: 11).

Las intervenciones más explícitamente artísticas de Sarfatti comenzaron en 1909, cuando empezó a escribir una columna sobre arte en el periódico socialista L'Avanti. El objetivo de Sarfatti era proponer una forma artística a la vez moderna e italiana, independiente de los modelos extranjeros $y$, por lo tanto, un clasicismo mediado por el simbolismo antes que por la vanguardia propuesta por los futuristas. Entre los pintores que Sarfatti defendió en ese momento estaban el scapigliato Tranquillo Cremona, el divisionista Gaetano Previati y el impresionista Antonio Mancini. "Clasicismo" significaba armonía, equilibrio y énfasis en la comunicación con el público, mientras que "simbolismo" implicaba un deseo de alejarse de la llana reproducción de la realidad para buscar una forma de expresión más elevada. La modernidad y la tradición constituyen, por tanto, categorías centrales en el pensamiento estético de Sarfatti desde sus primeras intervenciones.

Después de que Italia entrara en la Primera Guerra Mundial en 1915, Sarfatti - que perdería a su hijo de 18 años, Roberto, en la guerra - continuó interviniendo en el campo artístico. Según ella, durante la guerra el arte fue convocado a tomar un papel político y palingenético para unificar la nación italiana y preparar su futuro de posguerra. Así, Sarfatti revaloró al recién fallecido Umberto Boccioni, por ejemplo, cuyas obras de 1916 se alejaban de los experimentos más radicales de la vanguardia y más bien redescubrían la figuración. Por esta razón, según la periodista, podía considerársele como un clasicista moderno: un "hijo bueno y robusto y legítimo de la gran tradición artística italiana" (Sarfatti, Gli avvenimenti: 1).

Entre 1917 y 1932 Sarfatti colaboró con la sección cultural de II Popolo d'Italia, el periódico fundado por Mussolini en 1914 para remarcar su separación del Partido Socialista y su posición intervencionista, y portavoz oficial del régimen fascista desde 1922. En su columna de arte y literatura "Le cronache del venerdi" (Las crónicas de los viernes), Sarfatti propuso una idea de cultura como matriz para legitimar al estado fascista a través de la construcción de un estilo nacional. Los artículos de Sarfatti en II Popolo d'Italia allanaron el camino para la fundación del grupo Novecento milanese, que surgió en septiembre de 1922, unas semanas antes de la Marcha sobre Roma. Los artistas que Sarfatti defendió encarnaron una forma del clasicismo como expresión de la tradición italiana y, al mismo tiempo, representaron una ruptura y un nuevo comienzo después de la guerra. Mientras que otras formas de la tendencia artística de la "restauración del orden" italiana, como Valori Plastici, eran deliberadamente apolíticas, el movimiento de Sarfatti se alineó explícitamente con el partido fascista y sus valores, pero evitando la propaganda directa.

Formaron parte del Novecento milanese siete artistas radicados en Milán: Leonardo Dudreville, Achille Funi, Anselmo Bucci, Piero Marussig, Ubaldo Oppi, Mario Sironi y Emilio Malerba. Tras el sangriento conflicto global, descartaron los elementos perturbadores y provocadores de la vanguardia para redescubrir en el Renacimiento Italiano (de ahí el uso de un término semejante a "Quattrocento" o "Cinquecento") y en la tradición artística del siglo XIX las fuentes para un arte que pudiera reanudar el diálogo con el público. Esto significó un retorno a géneros que la vanguardia había evitado - como el retrato, la naturaleza muerta y el paisaje - y a una estética figurativa sólida y monumental. A pesar de 
no siempre compartir una estética similar, estos artistas acordaron comportarse como un grupo y, por lo tanto, participar en exhibiciones únicamente de manera colectiva. Sarfatti se encontró en la incómoda posición de fungir como empresaria, agente y propagandista del Novecento, mientras continuaba su trabajo como supuesta crítica independiente de arte. Esta contradicción terminaría con su carrera en la Italia fascista.

El grupo fue presentado públicamente en una exposición en la milanesa Galleria Pesaro (propiedad de Lino Pesaro) en 1923, a la que asistió el recién nombrado Primer Ministro, Benito Mussolini. Durante la inauguración Mussolini pronunció un famoso discurso en el que afirmó: "Declaro que la idea de fomentar algo que pueda parecerse a un arte del Estado está lejos de mí. El arte está dentro de la esfera de lo individual. El Estado tiene un solo deber: no sabotear, ofrecer condiciones humanas a los artistas, alentar desde un punto de vista artístico y tradicional" (II Popolo d'ttalia, Marzo 27, 1923). Desde esta temprana etapa, la opinión de Mussolini sobre el Novecento ya era contraria a la visión que Sarfatti tenía sobre el movimiento y sobre el papel de liderazgo que había previsto para ella misma. Además, el mandato general del Novecento (exponer en grupo en lugar de individualmente) ya resultaba demasiado estricto para algunos artistas, y el grupo terminó por disolverse en 1924, cuando Oppi decidió tener una exhibición por separado en la Bienal de Venecia.

A pesar de la implosión del Novecento milanese y aunque ella no ostentaba una posición oficial en el sistema artístico fascista (ninguna mujer lo hacía todavía), la influencia de Sarfatti continuó creciendo. Entre 1925 y 1933 dirigió la revista mensual Gerarchia, fundada por Mussolini como plataforma privilegiada para el debate sobre la naturaleza intelectual del fascismo. Sarfatti formó también parte de la junta directiva de la Bienal de Venecia y de la Trienal de Monza, entre otras destacadas exposiciones artísticas cooptadas por el régimen.

El año de 1926 fue fundamental para la carrera de Sarfatti. En ese año se publicó la edición italiana de su biografía de Mussolini, Dux. Casi una hagiografía, el libro logró dar coherencia a las opiniones políticas de Mussolini; una coherencia de la que en realidad carecían, puesto que eran animadas mucho más por intereses tácticos cambiantes que por una ideología sistemática. Ese mismo año Sarfatti inauguró, de nuevo en presencia de Mussolini, la primera exposición del refundado Novecento italiano, una coalición de artistas mucho más grande que la presentada en 1923. En las muestras del Novecento italiano participaron más de cien pintores y escultores italianos tan diversos como Baccio Maria Bacci y Massimo Campigli, Carlo Carrà y Felice Casorati, Antonio Donghi y Osvaldo Licini. Estos artistas fueron reunidos no por mostrar similitudes estéticas entre sí, sino por su prestigio y aspiración a representar una Italia fascista renovada a través del arte. A pesar de sus diferencias, estos artistas compartían un compromiso con la estética figurativa y los géneros tradicionales; énfasis en la solidez de los volúmenes y la claridad; y austeridad de medios, lo que pretendía demostrar rigor y disciplina. El Novecento Italiano trató al arte como una iniciativa intelectual elitista y altamente sofisticada que, sin embargo, aspiraba a establecer un diálogo con el público al evitar la abstracción, la violencia y los significados oscuros.

A diferencia de otros críticos de arte italianos de la época, enfocados en su mayoría en el mundo del arte nacional o, a lo sumo, en un diálogo cultural con Francia o Alemania, Sarfatti tenía una marcada vocación internacional y fomentaba la difusión del Novecento Italiano fuera de Italia, una forma de "colonización cultural", en palabras de Daniela Ferrari (Ferrari, 2018: 51-65). Viuda desde 1924, 
políglota, independiente y en excelente posición económica, Sarfatti fue además una elocuente oradora, como se hace evidente en las muchas fotos en las que se le retrató mientras cautivaba a audiencias por toda Europa, las Américas e incluso Egipto.

Tras la primera exposición del Novecento italiano, las obras de los artistas que habían participado en esta muestra se exhibieron sistemáticamente en el extranjero. Si bien la muestra de 1926 había resultado un éxito económico, el mercado del arte italiano aún se encontraba en pleno desarrollo; las exposiciones fuera de Italia podían entonces representar un ingreso significativo para los artistas del Novecento. En 1926, el Novecento italiano - una etiqueta que en realidad significaba "arte moderno italiano apoyado por Sarfatti" - era exhibido en París; en 1927, en Zurich y Ginebra, Hamburgo, Amsterdam y La Haya; en 1928, en Madrid y Lipsia; en 1929, en París, Niza, Ginebra y Budapest; en 1930, en Basilea, Berna y Berlín. Estas exhibiciones permitieron a Sarfatti posicionarse como una especie de embajadora artística no oficial del fascismo. "No oficial", porque sus exposiciones a menudo no eran respaldadas por el Sindicato de Artistas, sindicato que el fascismo había implementado para organizar a todos los profesionales de las artes visuales. Sarfatti comprendió desde el principio que el estado fascista necesitaba desplegar la cultura, la literatura y las artes si deseaba crear consenso para el régimen, a nivel nacional e internacional. Un consenso, no obstante, que, fiel a los orígenes de clase de Sarfatti, se filtraba desde los artistas hacia la clase obrera italiana, en lugar de involucrarla activamente. Fue ésta, junto con la creciente misoginia y antisemitismo, la razón de la marginación de Sarfatti y su eventual destitución.

Sarfatti esperaba que el Novecento italiano se convirtiera en el arte oficial del régimen y le proporcionara al fascismo una estética reconocible y una forma de representación simbólica. A partir de 1929 se mudó a Roma desde Milán, a donde había vivido desde 1902, para participar más activamente en la vida cultural del fascismo. Aunque evitó cualquier programa estético explícito para el Novecento, los describió como "artistas fascistas", es decir, "revolucionarios de la restauración moderna tanto en el arte como en la vida social y política". A pesar del temprano apoyo que mostró Mussolini al movimiento, el Duce se negó a comprometerse con una estética fascista específica. Sobre todas las cosas, Mussolini quería evitar la alienación de figuras importantes como el líder futurista F.T. Marinetti, el crítico y organizador cultural Cipriano Efisio Oppo, y el fascista de derecha Roberto Farinacci, entre otros críticos de la influencia de Sarfatti. Aunque también promovieron diferentes estilos artísticos y discreparon con Sarfatti en cuestiones estéticas, Marinetti, Oppo y Farinacci cuestionaron sobre todo su prominente $-y$, en su opinión, inmerecida - posición dentro del mundo artístico fascista (Del Puppo, 1995: 198; Bottai, 1940; Fossati, 1982: 175-259; Salvagnini, 1988).

Sobre todo, lo que fue criticado fue el hecho de que el Novecento Italiano representara al arte italiano en el extranjero a través de sus exposiciones internacionales, al dar la impresión de que el movimiento de Sarfatti era lo más representativo del arte se producía en Italia y que tenía un imprimátur oficial, a pesar de ser organizado por un comité privado y no por el Estado.

Esta situación llegó a un punto crítico en 1929, cuando Mussolini le envió a Sarfatti una carta prohibiéndole explícitamente decir "que tu Novecento [énfasis mío] es la proyección artística del fascismo". El pluralismo artístico del régimen respondía a la negativa del fascismo a ser restringido y confinado por una única posición política, y a su ambición de lograr expresar las múltiples aspiraciones de la sociedad italiana. Mussolini, en resumen, no quería patrocinar a un grupo en lugar de otro, sino transformar en fascistas a todas las iniciativas artísticas. 
Sin embargo, aunque el movimiento fue duramente criticado en Italia, fuera del país el Novecento parecía la única propuesta cultural italiana interesada en interactuar con el público extranjero. La exposición de 1930 en Buenos Aires (organizada mientras Sarfatti se defendía de las sistemáticas acusaciones de nepotismo y demás ataques contra el Novecento) marca el apogeo de las intervenciones fuera de Italia del movimiento, debido a su alta calidad, la recepción que tuvo y el impacto que produjo en la prensa italiana y argentina.

\section{Precedentes}

La exposición del Novecento en 1930 en Buenos Aires no fue la primera vez que llegó a Argentina una empresa cultural inspirada por el fascismo - que no patrocinada por él, ya que los fondos para la muestra de 1930 provinieron de la comunidad ítalo-argentina, como se verá más adelante.

En 1924 la Nave Italia visitó varios países latinoamericanos con grandes comunidades de emigrantes italianos: Brasil, Uruguay, Argentina, Chile, Perú, México y Cuba. La expedición, bajo el patrocinio de Gabriele D'Annunzio y Benito Mussolini, tenía como objetivo formar alianzas comerciales con mercados locales emergentes y vender arte tradicional a emigrados italianos. Sin embargo, el recién formado gobierno fascista también apoyó este proyecto para establecer en América Latina una red de camisas negras comprometidos. La propaganda fascista, especialmente después del asesinato del diputado socialista Giacomo Matteotti a manos de sicarios fascistas en junio de 1924, fue un elemento clave dentro de la expedición. Por esa razón fue duramente criticada en algunos medios latinoamericanos. Por ejemplo, los anarquistas y estudiantes universitarios chilenos protestaron durante los discursos oficiales italianos en Valparaíso y Santiago; el Partido Comunista mexicano organizó un boicot contra el barco fascista con la ayuda de los muralistas Xavier Guerrero, David Alfaro Siqueiros y Diego Rivera (Belli, 1925: 304; El Machete, 1924). Se aprendió una lección: aunque el régimen fascista mantenía un interés en la región, era importante enmarcar cualquier expedición cultural en términos de "Italia" y no de "fascismo", para evitar alienar a segmentos importantes de las comunidades de emigrantes.

Tampoco fue en la muestra de Amigos del Arte de 1930 la primera vez en que el público argentino había encontrado la pintura de la "restauración del orden" italiana, ya que ejemplos de la misma circulaban en Buenos Aires desde mediados de la década de los veinte. Sandro Piantanida, el representante de las editoriales milanesas Ricordi y Mondadori, fue un personaje clave en la organización de la exposición en Amigos del Artes. Piantanida era un editor proveniente de Milán que en ese momento residía en Buenos Aires, donde había establecido una editorial que vendía libros italianos; conoció personalmente al artista argentino Emilio Pettoruti y publicó una monografía sobre él en 1924. Antes de emigrar a Argentina, Piantanida había ayudado a fundar dos prestigiosas galerías de arte moderno en Milán: Bottega di Poesia y Galleria Scopinich (De Sabbata, 2016). Así pues, estaba bien conectado con el medio cultural milanés, epicentro de las actividades de Sarfatti y el Novecento.

Piantanida fue el encargado de vender en Argentina algunos cuadros del Novecento italiano propiedad de la Galleria Scopinich. El editor milanés es una de las posibles fuentes del arte italiano de entreguerras para las colecciones argentinas. De hecho, en mayo de 1928 Leonardo Staricco y Pettoruti organizaron en la galería Boliche de Arte una exposición de 22 obras del Novecento, muchas de ellas de la colección de Giovanni Rolleri, otro actor importante en la organización de la muestra de Amigos del Arte (Nosotros, Abril 1928): 79-80; Constantín, 2000: 215-216). Entre los artistas que expusieron había algunos que 
también se incluirían en la exposición del Novecento: Ardengo Soffici, Ugo Bernasconi, Alberto Salietti, Felice Dani, Raffaele de Grada y Lorenzo Viani.

En el catálogo, Starico enmarcaba al Novecento como un movimiento que se había mantenido "en los márgenes del zigzagueo de las nuevas tendencias... a través de la plasticidad pura". Un periodista argentino describió estas obras como "cerebrales y teóricas, trascienden las emociones espontáneas con el rigor de sus principios plásticos" (Constantín, 1998: 170). El público argentino de clase media ya conocía entonces el elegante clasicismo del Novecento que, enmarcado de manera adecuada, era una opción relativamente segura para mostrar la cultura italiana sin ofender la sensibilidad política de diferentes sectores de la sociedad argentina.

Sin embargo, el interés argentino sobre Italia no era correspondido entre los artistas italianos. El ex futurista Pettoruti había vivido varios años en Italia y conocía muy bien a los artistas italianos modernos, incluyendo a varios miembros del Novecento (Sullivan, 2004: 31-78; Kaplan, 2014). Después de regresar a Argentina en 1924 presentó a su público argentino el arte moderno italiano: escribió sobre Soffici, Carrá, Depero y otros en el periódico vespertino Crítica (Baur, 2010). Sin embargo, cuando en 1928 Pettoruti invitó a varios artistas italianos a enviarle algunos dibujos o pequeñas pinturas para organizar una exposición en Argentina, ninguno de ellos respondió. Por su parte, el conocimiento que tenía Sarfatti sobre la escena artística argentina era extremadamente superficial. Los únicos artistas argentinos que mencionaba en entrevistas eran Quinquela Martín - autor de algunas reproducciones que ella había adquirido y artista que había viajado a Italia en 1929 y protagonizado una exitosa exposición en el Palazzo delle Esposizioni en Roma - y Pettoruti, a quien Sarfatti había conocido en Milán a principios de los años veinte. Su visita a Argentina le ofrecería la posibilidad de aprender sobre el arte argentino. Sin embargo, aunque se reunió con artistas locales como parte de sus actividades en Buenos Aires, no manifestó ningún interés en presentar a artistas argentinos al público italiano y rara vez mencionó alguno de sus nombres en los artículos que publicó tras su regreso a casa.

\section{Una curaduría transatlántica}

La organización de la exposición de Novecento en Amigos del Arte fue un asunto verdaderamente transatlántico que llevó más de tres años de complicada correspondencia entre Buenos Aires, Roma y Milán. La iniciativa para la exposición del Novecento en Buenos Aires no provino de Sarfatti, a pesar de su proyección internacional. Más bien, fue un grupo de periodistas y empresarios italianos con sede en Argentina quienes vieron la pertinencia de realizar una muestra en el país sudamericano, y desde 1927 se pusieron en contacto con varios intelectuales italianos para impulsar una muestra de arte moderno italiano en Buenos Aires.

La primera oportunidad se dio en 1927, cuando tuvo lugar en Buenos Aires una exposición de libros italianos, organizada por Piantanida y el periodista Lamberti Sorrentino (Dal Quattrocento al Novecento, 1927). Sorrentino era un periodista fascista que había llegado a Buenos Aires, como Piantanida, a mediados de los veinte. La Prima Mostra del Libro Italiano a Buenos Aires se centró en última instancia sólo en los libros, pero originalmente se suponía que incluiría también una muestra de pinturas. Fue en estas circunstancias que Piantanida se puso en contacto por primera vez con el Comitato del Novecento Italiano, aunque los artistas mostraron tal desinterés por exponer en la Argentina que Piantanida decidió posponer la exposición de pintura. 
Sorrentino y Piantanida continuaron alentando incansablemente una exposición de arte moderno italiano en Argentina, incluso cuando los actores culturales italianos se mostraron reticentes a participar en ella. Desde la gestación de la exposición del Novecento en Buenos Aires quedó claro que Amigos del Arte era el lugar más adecuado para una muestra de arte moderno italiano, debido a su prestigio y al interés en la cultura italiana que muchos de sus miembros mostraban. De hecho, Amigos del Arte estuvo estrechamente vinculado con el ambiente intelectual que gravitaba alrededor de la revista Martín Fierro (1924-27) cuya simpatía hacia la cultura italiana era considerable. Entre sus colaboradores se encontraban Pietro Illari, un artista futurista, así como Piantanida, Sorrentino y Sandro Volta, los tres directamente involucrados con la organización de la exposición del Novecento.

A su llegada a Buenos Aires en noviembre de 1924, por ejemplo, Volta comenzó a escribir para Martin Fierro una serie de artículos sobre los más recientes desarrollos literarios y artísticos en Italia, en los que mencionaba a Ardengo Soffici, Carlo Carrá y Achille Lega, todos incluidos en la muestra de Amigos del Arte. Fue también gracias a la insistencia de Martín Fierro que F.T. Marinetti extendió su viaje de 1926 a Brasil y visitó a Buenos Aires. Durante su viaje inauguró una exposición de arte argentino en Amigos del Arte y se reunió con Sorrentino y Piantanida. Sin embargo, las obras de Emilio Pettoruti, Xul Solar y Norah Borges que se exhibian en ella demostraron claramente que el futurismo de Marinetti había sido superado, y precisamente en la línea indicada por los artistas de la "restauración del orden" que serían expuestos en 1930.

Los intereses intelectuales de Martín Fierro y Amigos del Arte fueron complementados por los intereses políticamente más estratégicos de algunos destacados emigrantes italianos, incluyendo no sólo a los recientemente emigrados Piantanida y Sorrentino, sino también a Giovanni Rolleri o, como llegó a ser conocido en Argentina, Juan de Rolleri (Starosta Galante, 2016). Rolleri fue un miembro activo de la comunidad italiana, especialmente durante la Primera Guerra Mundial, y estaba interesado en promover la cultura italiana en Argentina. Era ampliamente respetado en la comunidad ítalo-argentina, que a finales de los veinte estaba profundamente dividida por cuestiones políticas. Rolleri era un coleccionista de pintura moderna italiana y mantuvo correspondencia con artistas como Libero Andreotti, Antonio Maraini y Ardengo Soffici, cuyas obras había adquirido en la Bienal de Venecia o contactando directamente a los artistas. Aunque murió poco más de un mes antes de la inauguración de la exposición, fue recordado por la prensa como la verdadera inspiración de la muestra.

En octubre de 1928, Lamberti Sorrentino se puso en contacto en nombre de Rolleri con el artista y crítico italiano Ardengo Soffici - hacia quien se dirigió como "camarada y colega" para destacar su filiación fascista común - con un plan detallado para realizar una exposición de arte italiano en Buenos Aires. Le escribió que, después de haber publicado en la prensa argentina un artículo sobre el arte italiano, artistas y prestigiosos galeristas locales como Federico Carlos Müller se mostraban interesados en una exposición de arte italiano en Buenos Aires; un signo de que el mercado argentino se encontraba listo para tal exposición. Así, Sorrentino lanzó una propuesta concreta: Amigos del Arte ofrecería sus instalaciones de forma gratuita, obteniendo el $10 \%$ de las obras vendidas, para la organización de una "exposición de la pintura italiana de los siglos XIX y XX, o incluso sólo del siglo XX, organizada y posiblemente acompañada por Ardengo Soffici". 
El programa debería ser autopatrocinado, escribió Sorrentino, para evitar cualquier ambiente de "patrioterismo" explícito que pudiera alienar el medio intelectual argentino. La exposición, "para alcanzar su máxima eficacia, debería ser sólo un evento artístico", subrayó Sorrentino. Sin embargo, los gastos inmediatos se pagarían mediante una discreta recaudación de dinero entre los miembros más comprometidos políticamente de la comunidad italiana, con la ayuda del Fascio local y la Embajada de Italia. En resumen, el componente fascista de esta iniciativa tuvo que ser ocultado cuidadosamente; por ejemplo, no se informó a Amigos del Arte. Sorrentino concluyó: "Expreso mi convicción personal y la de los más cercanos a mí: ninguna exposición oficial, excepto en casos extremos, y una selección de lo mejor que tenemos de los siglos XIX y XX; realmente lo mejor porque aquí están en posición de juzgar" (Lamberti Sorrentino para Ardengo Soffici, Octubre 22, 1928.).

Soffici no estaba interesado en la exposición de Buenos Aires, así que le pasó el mensaje a Sarfatti. Como le escribió, a pesar de la pluralidad del arte fascista italiano, en su opinión el Novecento era "el mejor representante de nuestras diversas corrientes artísticas y de la complejidad pictórica y escultórica italiana de estos tiempos" (Ardengo Soffici para Margherita Sarfatti, Diciembre 30, 1928). Sin embargo, siguiendo el consejo de Sorrentino, Soffici fue inflexible en cuanto a que la exposición debía hacerse "fuera de los círculos oficiales y diplomáticos, ya que recuerdo el fenómeno de la Nave Italia y las muchas meteduras de pata que se cometieron entonces". A pesar de eso, en una carta al artista Carlo Carrà - una de cuyas pinturas Rolleri quería adquirir para su colección, y quien se había quejado de la creciente influencia de Sarfatti en el arte italiano - Soffici explicó que había renunciado a la organización de la muestra de Buenos Aires "porque he aprendido que el público allí es bastante grosero o snob, admirador de los blagues franceses; porque no fue posible representar el arte italiano (como [los organizadores] querían) con una exposición grupal restringida y bien escogida; porque, finalmente, es imposible en Italia concluir algo entre artistas debido al estúpido anarquismo, la confusión y la susceptibilidad que gobierna nuestra clase... Y porque los impulsores [argentinos] al final querían algo que se pareciera al Novecento" (Ardengo Soffici para Carlo Carrà, Abril 11, 1929).

Sorrentino se mantuvo firme en que sólo debían ser enviadas las mejores y más representativas obras de estos artistas. A pesar de la pobre opinión de Soffici sobre el público argentino, Sorrentino y Piantanida insistieron en que el público local sería capaz de discernir la calidad de lo que se exhibiría. Sarfatti hizo caso a su recomendación y, de hecho, la exposición fue notable por su calidad, tanto así como para que pudiera ser considerada una de las mejores muestras del arte del Novecento italiano fuera de Italia.

Sin embargo, en general a los artistas del Novecento no les entusiasmaba esta exhibición y preferían centrarse en exposiciones dentro de Italia - como la Bienal de Venecia de 1930, la Trienal de Monza de 1930 y la Cuadriennale Romana de 1931 - y Europa. Sarfatti se vio obligada a escribir a Mario Sironi, uno de los miembros más prominentes del Novecento desde 1922, exhortándolo a él y a sus colegas "por tu honor de artista, fascista, italiano y amigo" a darle diez de sus mejores obras. Añadió melodramáticamente: "...porque si tengo que ir hasta allá y avergonzar a Italia, jsería mejor que me disparase!" (Margherita Sarfatti para Mario Sironi, Mayo 28, 1930).

Sarfatti supuso que una sede sudamericana añadiría prestigio al Novecento italiano y a la Italia fascista, y que protegería a su movimiento de sus críticos italianos. Por eso trabajó incansablemente para reunir a los artistas del Novecento y organizar una exposición de mucha calidad que reflexionaría 
positivamente sobre la Italia fascista y silenciaría las voces internacionales contrarias al régimen, así como las invectivas en Italia a las propias actividades de Sarfatti.

\section{Novecento Italiano en Buenos Aires}

La exposición del Novecento en Amigos del Arte fue una de las muestras más amplias del movimiento en el extranjero, al incluir obras de más 46 artistas diferentes. Mostraba un panorama bastante incluyente del arte italiano de la época y exhibía obras de mucha calidad que habían sido muy aplaudidas en Italia y Europa. La elección de las 208 cuadros que se enviarán a Buenos Aires fue realizada personalmente por Sarfatti y los artistas Achille Funi (que visitó los estudios de artistas en Roma) y Mario Sironi (que visitó los de Milán y Turín). Debido a que se trajeron más obras de las que se podían exhibir en las salas proporcionadas por Amigos del Arte, algunas de las pinturas fueron agregadas en una segunda etapa. La alta calidad de las obras en exposición fue señalada por los argentinos, quienes destacaron que "por primera vez un país europeo no nos está enviando restos coloniales irrelevantes, sino que nos ofrece una rigurosa selección de... lo mejor de su producción" (Sarfatti, Bilancio della Mostra).

Cinco de las obras pre-metafísicas de Giorgio de Chirico, todas realizadas en 1909, fueron las primeras pinturas de la exhibición. Aunque no era uno de los siete artistas originales del Novecento, de Chirico había sido incluido en muchas de las exposiciones del movimiento desde 1926, tanto en Italia como en el extranjero. Su estética puede parecer contraria a los volúmenes clasicistas que asociamos con la restauración del orden de entreguerras, pero la presencia de Chirico en la muestra del Novecento transmite un hecho clave sobre el movimiento de Sarfatti en 1930: que más que una estética común, reunía a artistas con prestigio nacional e internacional que reflejaban bien la influencia del fascismo en el campo cultural.

La exposición incluyó sólo a tres de los miembros del grupo Novecento milanese: Achille Funi, Piero Marussig y Sironi. Las pinturas de Antonio Donghi y Carlo Socrate expresaban un realismo mágico relacionado a la Neue Sachlichkeit alemana. Por el contrario, otros artistas como Carlo Carrà, Ardengo Soffici y Giorgio Morandi reelaboraron géneros del siglo XIX como el paisaje y la naturaleza muerta. Se incluyeron pinturas neofuturistas de Enrico Prampolini y Pippo Rizzo. Otros pintores como Massimo Campigli presentaron pinturas hieráticas y de inspiración etrusca. Se incluyeron en la exposición diez inquietantes obras figurativas de Felice Casorati que fueron de las más admiradas por la prensa argentina, que describió a su obra como una que poseía "la belleza y el equilibrio de los clásicos" y una "gracia fina y penetrante". También estuvieron expuestos artistas italianos destacados que residían en París, como Filippo de Pisis, Mario Tozzi, Gino Severini y Renato Paresce.

Dos obras, La casa rossa de Carrà (1927) y Rosanna desnuda de Casorati (1929), entraron en las colecciones del Museo de Bellas Artes de Buenos Aires, mientras que coleccionistas argentinos e italianos migrados adquirieron muchas de las obras expuestas. Se había pedido a los artistas que mantuvieran bajos los precios para fomentar las adquisiciones. La estrategia funcionó tan bien que al final de la vernissage se habían vendido ya 14 obras. 


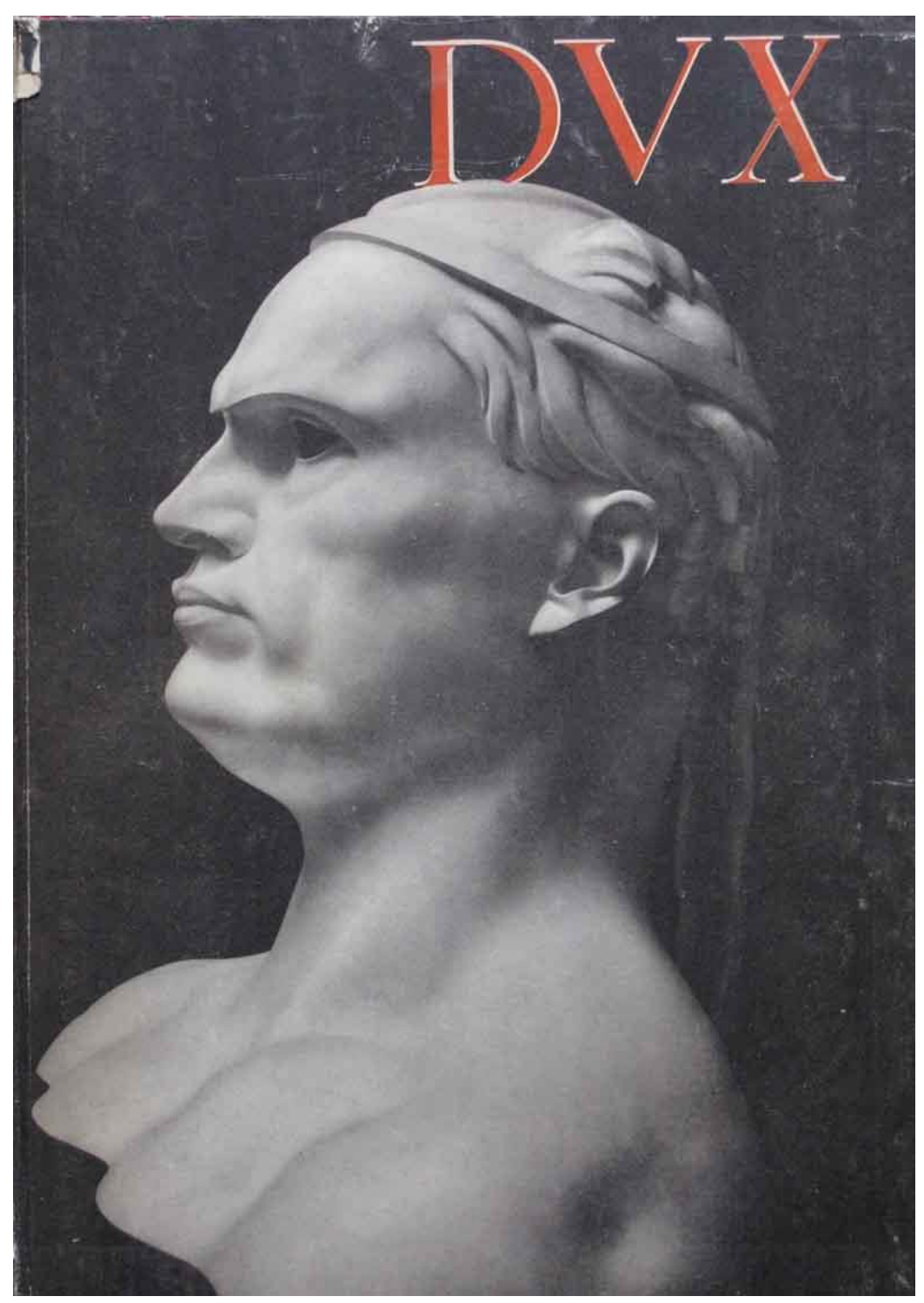

Fig.2. Margherita Sarfatti, Dux (Milan: Mondadori, 1929), con o busto hecho por Adolfo Wildt en la portada. Arquivo da autora.

Las únicas referencias explícitas al régimen fascista en la exposición fueron un retrato de Mussolini realizado por Massimo Campigli, y la única escultura en la muestra, un busto de Benito Mussolini por Adolfo Wildt, que abría el catálogo con una fotografía de página completa. El primero, ahora perdido, también había sido incluido en la Segunda Exposición del Novecento de 1929, la segunda gran exposición del Novecento Italiano en Milán. Hecho originalmente en 1928, las descripciones de coetáneos nos hacen pensar que pudo haber sido bastante hierático, probablemente muy similar a otros retratos de inspiración etrusca de destacados intelectuales italianos que Campigli estaba pintando en ese momento. 
Las copias de la segunda, por el contrario, todavía existen porque fue una de las imágenes más reconocibles de Mussolini hechas en la década de 1920. Sarfatti había encargado este busto en 1923 para celebrar el primer aniversario de la Marcha en Roma, e ilustró muchas de las ediciones de Dux [fig.2]. Como se podía leer en el catálogo de la muestra de Buenos Aires, que sólo fue publicado en italiano e impreso en Italia, la inclusión de este busto pretendía "evocar para los italianos en tierras lejanas la imagen del Creador de la Nueva Generación Italiana”. El busto retrata a Mussolini como un ciudadano romano vistiendo la infula, un tocado sacerdotal.

Lo que pasó con este busto, sin embargo, y si estuvo realmente en la exhibición es un misterio. A pesar de sus impresionantes dimensiones, el busto sólo se menciona superficialmente en un par de artículos argentino. Parece que los organizadores argentinos decidieron ocultarlo, ya que no aparece en ninguna de las fotografías que tenemos de la instalación. Sarfatti y el Comitato del Novecento seleccionaron a los artistas expuestos, pero la distribución de las obras en los cinco salones de Amigos del Arte estuvo a cargo de tres personajes clave de la cultura argentina: el ex alcalde de Buenos Aires, Manuel Güiraldes, y el artista Alfredo Gonzáles Garaño, miembros de Amigos del Arte y de las élites económicas y políticas argentinas, y Emilio Pettoruti.

En sus memorias, publicadas en 1968, Pettoruti escribió que Sarfatti le confió las decisiones curatoriales que se tomaron inmediatamente antes de la inauguración y que fue su decisión personal no exhibir el busto de Wildt, "no sólo porque era de Mussolini... sino porque era un trabajo repulsivo, pretencioso y frío que chocaba con el resto del arte en exhibición" (Pettoruti, 1968: 224). Según Pettoruti, Sarfatti tuvo un verdadero colapso nervioso en el que lloraba: "I Duce, il mio Duce", pero finalmente tuvo que aceptar la decisión de Pettoruti. Puede que Pettoruti haya exagerado al describir los hechos. De hecho, el busto de Wildt ya no estaba incluido en la lista de obra publicada en español y probablemente impresa en Buenos Aires varios días antes de la inauguración. Otro artículo mencionó que cuando Sarfatti vio la disposición de las obras en exhibición se felicitó con los curadores, y "no solicitó que se cambiara de lugar una sola pintura" (II Mattino d'Italia, Gli Italiani e il successo dell'iniziativa) Cualquiera que sea la verdad, es probable que el busto de Wildt no estuviera a la vista, pues si lo hubiera estado habría recibido mucha atención de la prensa, como sucedió en todos los lugares en los que fue expuesto.

De hecho, para alcanzar a un público más amplio en Buenos Aires y evitar las insensibilidades políticas de la Nave Italia que había alienado a los emigrantes italianos no fascistas, Sarfatti suavizó las asociaciones fascistas de la exposición y destacó su carácter nacional antes que ideológico. Esta había sido una condición para la exposición desde que se le sugirió por primera vez a Soffici: tenía que presentarse como una iniciativa "italiana" y no fascista, aunque el Fascio local la apoyara económicamente, Sarfatti hubiera visitado las asociaciones fascistas locales durante su estancia, y su compromiso con el régimen (y relación personal con Mussolini) fueran bien conocidas en Argentina. La justificación de esta medida era doble: para evitar que se exasperara aun más a Mussolini y a los críticos contra la Sarfatti; y para impedir nuevas divisiones en la comunidad italiana argentina que, como muchas otras, se había escindido políticamente tras el advenimiento del fascismo.

Mussolini estaba incluido en el comité honorario de la exposición, al igual que el embajador italiano Pignatti da Custoza. Sin embargo, cuando el secretario del Partido Nacional Fascista ofreció escribir la introducción del catálogo, Sarfatti se negó, precisamente para evitar estrechar el vínculo entre el 
Novecento italiano y el partido. Sarfatti misma escribió la introducción y no habló en el catálogo sobre la orientación política de los artistas, limitándose a enmarcarlos como la expresión de una "italianidad moderna". Adoptó este mismo enfoque en las numerosas entrevistas que le realizaron en Argentina, en las que presentó al Novecento no como el equivalente artístico del fascismo sino como la expresión de un carácter nacional italiano inmutable. El paso de "italiano" a "fascista" no era difícil de hacer, pero rara vez fue explicitado por la propia Sarfatti en sus entrevistas con la prensa argentina, aunque sí lo hizo en las que dio en Italia. También la prensa ítalo-argentina hizo hincapié en la italianidad y no en el apoyo por parte del fascismo que los artistas del Novecento habían recibido. Un artículo publicado en $L a$ Nación, el periódico conservador más importante de Buenos Aires, describió a la exposición como la expresión de una "Italia renovada", y al Novecento como un movimiento "en el que la nueva Italia define su voluntad... una expresión nacional, histórica... que ilustra los aspectos más ricos y brillantes del genio italiano" (Mattino d'Italia, L'esposizione del 900 Italiano giudicata dalla critica argentina)

Sin embargo, mientras que en 1924 subrayar el componente fascista de la Nave Italia fue una decisión equivocada, en 1930 restar importancia al vínculo fascista de la exposición del Novecento resultó en una oportunidad perdida. La muestra se inauguró una semana después del golpe fascista de José Félix Uriburu, cuando los argentinos estaban muy interesados en la ideología de Mussolini. (Finchelstein, 2002; Azcona Pastor, 2010; Dalmazzo, 2010) El régimen pro-fascista de Uriburu estableció una dictadura militar con el primer golpe militar en la Argentina del siglo XX. El año 1930 fue realmente crucial para el desarrollo de la extrema derecha política en Argentina, fortaleciendo las relaciones culturales y económicas entre el país y Alemania e Italia. Italia fue el primer país que reconoció el gobierno de Uriburu. La propia Sarfatti participó en su toma de posesión, minimizando la violencia callejera que siguió, y describiendo el cambio político como "la liberación de una pesadilla".

Tras su regreso a Italia, Sarfatti escribió un artículo en el que analizaba para el público italiano la ola de "revoluciones" (término suyo, siguiendo la idea fascista de una "revolución conservadora") que estaban teniendo lugar a través de América Latina. Presentó el golpe de Uriburu como el equivalente de la toma de posesión de Mussolini en 1922, una "insurrección de gente joven y honesta en contra un régimen corrompido por la debilidad senil". En su opinión, países como Brasil y Argentina se encontraban en una posición ideal para entablar un diálogo cultural, político y económico con la Italia fascista, al haber resistido ante la Doctrina Monroe y la influencia estadounidense en la región gracias a sus golpes militares.

Intentando, quizás demasiado tarde, vincular su exhibición con el fascismo argentino, Sarfatti informó también que en las dos semanas que estuvo abierta la exposición del Novecento el público argentino sólo habló de dos cosas: "La revolución nacional y la exhibición italiana" (Sarfatti, Gerarchia: 1018). Ya fuera por esta pertinencia política o por una genuina curiosidad hacia el arte italiano, en efecto el público abarrotó las salas de los Amigos del Arte. Algunas fuentes mencionan más de 300 visitantes por día y la prensa argentina dedicó varios artículos a la exhibición, difuminando la línea entre lo "italiano" y lo "fascista" en su cobertura de la muestra.

En resumen, en 1930, cuando Sarfatti inauguró una exposición del Novecento italiano en Argentina, el régimen fascista italiano estaba plenamente establecido, pero aún no había comenzado sus iniciativas imperialistas en África. Debido a la "esencia latina" que Italia y América Latina supuestamente compartían, el régimen de Mussolini utilizó una estrategia colonial muy diferente de la que empleó en 
África, basada en el arte y la cultura más que en la ocupación militar y la explotación económica. La exposición en Buenos Aires del Novecento fue particularmente sintomática de las tensiones y desafíos presentes al intentar definir el arte fascista en Italia y en el extranjero. La traducción transatlántica de la "restauración del orden", operada por Sarfatti en esta exposición y luego continuada en su trabajo como crítica y organizadora de colecciones durante su exilio sudamericano, es un ejemplo de una "movilidad del modernismo" (Chalk, 2014; Montgomery, 2017) problemática y reaccionaria. Revela cómo las redes migratorias y la internacionalización de las formas artísticas definieron nuevas geografías de intercambio intelectual en el siglo XX. Estudios de casos como el de la muestra del Novecento en Buenos Aires subrayan el impacto de los proyectos transnacionales en la redefinición de los contextos artísticos locales, al tiempo que abordan el duradero impacto del nacionalismo tanto en la práctica artística como en la historia del arte.

\section{Referencias}

ALBIN, J. Disputas por la tradición: Adolfo Bellocq, ilustrador del Martín Fierro. Caiana, $n$. 11 2017. $<$ http://caiana.caia.org.ar/template/caiana.php? pag $=$ articles $\% 2$ Farticle_2.php\&obj=283\&vol=11 \#_edn2>.

ALCALÁ, M.L. La esquiva huella del futurismo en el Rio de la Plata: a cien años del primer manifiesto de Marinetti. Buenos Aires: Patricia Rizzo Editora, 2009.

ARTUNDO, P.; PACHECO, M.E. Amigos del Arte, 1924-1942. Buenos Aires, Argentina: Malba, Fundación Costantini, 2008.

AVANZI, B. and FERRARI, D. Un'eterna bellezza. Il canone classico nell'arte italiana del Primo Novecento. Milan-Madrid: Electa, 2017.

AZCONA PASTOR, J. M. Violencia política y terrorismo de estado en Argentina: del totalitarismo de José Uriburu 1930 a la dictadura militar 1976-1983: una visión bilateral. Madrid: Biblioteca Nueva, 2010.

BARISIONI, E. Viaggio alle fonti dell'arte: il moderno e l'eterno. Margherita Sarfatti 19191939. Treviso: Zel, 2018.

BASTOS KERN, M. L. A presença da arte italiana em Buenos Aires: O Novecento. In: DE RUGGIERO, A. História e narrativas transculturais entre a Europa Mediterrânea e a América. Porto Alegre: EDIPUCRS | EDUCS, 2017.
BAUR, S. and ALCALÁ, M.L. Pettoruti crítico en Crítica. Buenos Aires: Patricia Rizzo Editora, 2010.

BELLI, PIERO. Al di là dei mari... Firenze: Vallecchi Editore, 1925.

BEN-GHIAT, R. Fascist Modernities Italy, 19221945. Berkeley: University of California Press, 2001.

BOSSAGLIA, R. I/ Novecento italiano. Milano: Charta, 1995.

BOTTAI, G. Politica fascista delle arti. Roma: Signorelli, 1940.

BRAUN, E. Mario Sironi and Italian Modernism: Art and Politics under Fascism. Cambridge-New York: Cambridge University Press, 2000.

CANNISTRARO, P.; SULLIVAN, B. Duce's Other Woman. New York: Morrow, 1993.

CANNISTRARO, P. La fabbrica del consenso: fascismo e mass media. Roma-Bari: Laterza, 1975.

CHALK, B. Modernism and Mobility: The Passport and Cosmopolitan Experience New York: Palgrave Macmillan, 2014.

CIARLANTINI, F. Viaggio in Argentina. Milan: Alpes, 1929, p. 94-95.

COLOMBO, N. Le gallerie private milanesi protagoniste della storia di 'Novecento' 19201932. In: PONTIGGIA, E. and GIAN FERRARI, C. II Novecento milanese: da Sironi ad Arturo Martini, Milano: Mazzotta, 2003, p. 31-54. 
CONSTANTÍN, M.T., Italia en la nebbia. La Boca como residencia. In: WECHSLER, D. Italia en el horizonte de las artes plásticas. Argentina, siglos XIX y XX. Buenos Aires: Asociación Dante Alighieri, 2000, p. 190-219.

CONSTANTÍN, M.T., Todo lo sólido se petrifica en la pintura o la reformulación de la modernidad en Guttero, Cúnsolo y Lacámera. In: WECHSLER, D. Desde la otra vereda. Momentos en el debate por un arte moderno en la Argentina 1880-1960. Buenos Aires: CAIA, 1998, 157-178, 170.

CORRIERE DELLA SERA. II successo a Montevideo della mostra del Novecento Italiano, Milan (Diciembre 30, 1930).

CORRIERE MERCANTILE. Margherita Sarfatti reduce da Buenos Aires. Corriere Mercantile. Genoa (Octubre 6, 1930).

DALMAZZO, G. El primer dictador: Uriburu y su época Buenos Aires: Vergara, Grupo Zeta, 2010.

DE CAPRARIIS, L. 'Fascism for Export'? The Rise and Eclipse of the Fasci Italiani All'Estero, Journal of Contemporary History 35, n. 2 (Abril 1, 2000), p. 151-183.

DE SABBATA, M. Mostre d'arte a Milano negli anni venti. Dalle origini del Novecento alle prime mostre sindacali 1920-1929. Torino: Allemandi, 2012.

DEL PUPPO, A. Da Soffici a Bottai. Una introduzione alla politica fascista delle arti in Italia, Revista de História da Arte e Arqueologia, Campinas, n. 2, p. 191-204, 1995/6.

EL MACHETE, ¡Alerta trabajadores de Veracruz! ¡Boycot al Barco Fascista! (Agosto 21, 1924).

ESPOSIZIONE DEL PITTORE ARGENTINO BENITO QUINQUELA MARTIN. Palazzo delle Esposizioni, Roma. Rome: Selecta, 1929.

FERRARI, D. Novecento italiano all'estero: una colonizzazione culturale. In: FERRARI, D., and GIACON, D. Margherita Sarfatti. Milan: Electa, 2018, p. 51-65.

FINCHELSTEIN, F. Fascismo, liturgia e imaginario: el mito del General Uriburu y la Argentina nacionalista. Mexico: Fondo de Cultura Economica, 2002.

Transatlantic Fascism: Ideology, Violence, and the Sacred in Argentina and Italy, 1919-1945. Durham; London: Duke University Press, 2010.
FOTÍA, L. La crociera della nave Italia e le origini della diplomazia culturale del fascismo in America Latina. Rome: Aracne, 2017.

FRANZINA, E.; SANFILIPPO, M. Emilio Franzina and Matteo Sanfilippo. II fascismo e gli emigrati: la parabola dei Fasci italiani all'estero 1920-1943. Roma: GLF editori Laterza, 2003.

GENTILE, E. Le origini dell'ideologia fascista 1918-1925. Bologna: II Mulino, 1996.

GÜIRALDES, R. 13 obras de Emilio Pettoruti. Buenos Aires: Ricordi, 1924.

IL MATTINO D'ITALIA. Giudizi favorevoli alla Mostra del 900 Italiano, Buenos Aires (Septiembre 15, 1930).

Gli elementi di un successo. Buenos Aires (Octubre 1, 1930).

Gli Italiani e il successo dell'iniziativa. Buenos Aires (Septiembre 15, 1930).

Mostra del 900 italiano a Buenos Aires. Giudizi della stampa argentina. Buenos Aires (Septiembre 27, 1930).

Mostra del 900 Italiano. Buenos Aires (Septiembre 19, 1930).

. L'esposizione del 900 Italiano giudicata dalla critica argentina. Buenos Aires, (Septiembre 14, 1930).

Perdura l'interesse del pubblico attorno alla Mostra del 900 Italiano. Buenos Aires (Octubre 2, 1930).

Un trionfo dell'arte italiana moderna in Argentina. Buenos Aires (Septiembre 14, 1930).

KAPLAN, L. Crossing the Atlantic: Emilio Pettoruti's Italian Immersion, Art|@s Bulletin 3, no. 2: Highways of the South: Latin American Art (Fall 2014).

MAGALHÃES, A. G. Classicismo moderno. Margherita Sarfatti e o Novecento Italiano, entre Brasil e Estados Unidos. Revista de Italianística n. 37 (2018) p. 37-57.

MALVANO, L. Fascismo e politica dell'immagine Torino: Bollati Boringhieri, 1988.

MANTURA, B. and OSIO, B. Sartorio 1924 : Crociera Della Regia Nave Italia nell'America Latina. Roma: Ed. De Luca, 1999.

MARINETTI, F. T. Tournée nell'America del Sud maggio-giugno 1926. In: BERTONI, A. Taccuini 1915-1921. Bologna: Soc. Ed. II Mulino, 1987, p. 515-541. 
MARZORATI, S. Margherita Sarfatti. Saggio biografico. Como: Nodolibri, 1990.

MEO LAOS, V. G. Vanguardia y renovación estética: Asociación Amigos del Arte 1924-1942. Buenos Aires: Ediciones Ciccus, 2007, p. 121124.

MONTGOMERY, H. The Mobility of Modernism: Art and Criticism in 1920s Latin America. Austin: University of Texas Press, 2017.

MOSTRA DEL NOVECENTO ITALIANO, Buenos Aires: Amigos del Arte, 1930.

MOURE CECCHINI, L. The Nave Italia and the Politics of Latinità: Art, Commerce, and Cultural Colonization in the Early Days Of Fascism, Italian Studies 71, n. 4 (Octubre 1, 2016): 447476.

MUÑOZ, M. A. Los Artistas del Pueblo 19201930. Buenos Aires: Imago-Fundación Osde, 2008.

MUSSOLINI, B. Discorso di Benito Mussolini alla prima mostra del Novecento, II Popolo d'Italia (Marzo 27, 1923).

PETTORUTI, E. Un pintor ante el espejo. Buenos Aires: Solar, 1968, 128.

PONTIGGIA, E. Modernità e classicità: il ritorno all'ordine in Europa, dal primo dopoguerra agli anni Trenta Milan, Italia: B. Mondadori, 2008.

PREBISCH, A. Marinetti en los Amigos del Arte, Martín Fierro III, n. 30-31 (Julio 1926), p. 219221.

PRETELLI, M. II fascismo e gli Italiani all'estero, Passato futuro. Bologna: CLUEB, 2010.

PROGRESSO ITALO-AMERICANO. Una esposizione d'arte italiana in Argentina. New York (Noviembre 16, 1930).

RAGAZZI, F. Giorgio de Chirico nelle mostre di 'Novecento Italiano,' Metafisica n. 7-8 2008, p. 201-232.

SAITTA, S. Futurism, fascism and Mass-media: The Case of Marinetti's 1926 Trip to Buenos Aires, Stanford Humanities Review 7:1 (Summer 1999), p. 31-47.

SALVAGNINI, S. L'arte in azione. Fascismo e organizzazione della cultura artistica in Italia, Italia contemporanea n. 173 (Diciembre 1988), p. 5-21.
SANTINON, E. I Fasci Italiani all'estero. Roma: Settimo Sigillo, 1991.

SARFATTI, M. Bilancio della Mostra del '900 a Buenos Aires, Il Popolo d'Italia Milan (Octubre 24, 1930).

. La povertà delle terre ricche, Gerarchia n. 12 (Diciembre 1930), p. 1018-1025.

. Bilancio della Mostra del '900 a Buenos Aires. II Popolo d'talia. Rome (Octubre 24, 1930).

L'opera di Umberto Boccioni, Gli avvenimenti (Septiembre 24-Octubre 1, 1916).

SAVARINO ROGGERO, F. El amanecer del fascismo: el periplo continental de la «Nave Italia» 1924. In: BERTONHA, J.F. El fascismo en Brasil y América Latina: ecos europeos y desarrollos autóctonos. Mexico D.C.: INAH, 2013, p. 67-95.

SCHNAPP, J. and DE CASTRO ROCHA, J.C. Brazilian Velocities: On Marinetti's 1926 Trip to South America, South Central Review 13, n. 2/3 Julio 1, 1996: 105-156.

SECONDA MOSTRA DEL NOVECENTO ITALIAN. Milan: Palazzo della Permanente, 1929.

SECONDA MOSTRA DEL NOVECENTO ITALIANO: catalogo. Milano: Coi tipi del Cav. Enrico Gualdoni, 1929.

SEMINO, C. Víctor Cúnsolo 1898-1937. In: La Escuela de Arte de La Boca: sus grandes maestros. Buenos Aires: Dirección General Patrimonio e Instituto Histórico, 2012, p. 255279.

SORRENTINO, L. Encuesta sobre la influencia italiana en nuestra cultura parte 2, Nosotros 60 , no. 227 (Abril 1928), p. 80.

Una mostra del '900 a Buenos Ayres. Corriere di Sicilia (Octubre 1, 1930).

Una mostra del '900 a Buenos Ayres. Nostra intervista con Margherita Sarfatti, Corriere della Sicilia Catania (Octubre 1, 1930).

SPAINI, Al. Margherita Sarfatti, il Novecento e la Mostra di Buenos Aires, Italia Letteraria (Noviembre 9, 1930). 
STARICCO, L. Mi boliche de arte, Áurea: revista mensual de todas las artes a. I, n. 6-7 (OctubreNoviembre 1927), p. 51.

Boliche de arte n. 1. pintura italiana (Mayo 5, 1928).

STAROSTA GALANTE, J. The 'Great War' in II Plata: Italian Immigrants in Buenos Aires and Montevideo During the First World War, Journal of Migration History 2, n. 1 (Marzo 22, 2016), p. 57-92.

SULLIVAN, E. Pettoruti as Ex-Patriot: The Artist's Early Years in Italy. In: PERAZZO, N. and SULLIVAN, E. Emilio Pettoruti 1892-1971. Buenos Aires: Marca editora, 2004, p. 31-78.

URSO, S. Margherita Sarfatti dal mito del Dux al mito americano. Venezia: Marsilio, 2003.

VOLTA, S. Los 'martinfierristas' de Italia, Martín Fierro. Periódico quincenal de arte y crítica libre I (Noviembre 1924).

WECHSLER, D. Buenos Aires 'otra' modernidad, Estudios Ibero-Americanos PUCRS XXIII, n. 2 (Diciembre 1997): 195-208.

Impacto y matices de una modernidad en los márgenes. Las artes plásticas entre 1920 y 1945. In: BURUCÚA, J.E. Nueva historia argentina. Arte, sociedad y política. Buenos Aires: Sudamericana, 1999.

WECHSLER, D. Novecento sudamericano: relazioni artistiche tra Italia e Argentina, Brasile, Uruguay. Milano: Skira, 2003.

\section{Documentos de Archivo}

Sandro Piantanida para Alberto Salietti, Abril 2, 1927, Fondo Alberto Salietti, Archivi del Museo del '900-Milano.

Lamberti Sorrentino para Ardengo Soffici, Octubre 22, 1928. Fondo Alberto Salietti, Archivi del Museo del '900-Milano.

Ardengo Soffici para Margherita Sarfatti, Diciembre 30, 1928, Fondo Margherita SarfattiArchivio del '900- MART-Rovereto.

Ardengo Soffici para Carlo Carrà, Abril 11 1929, Fondo Carlo Carrá- Archivio del '900- MART.

Massimo Campigli para Alberto Salietti, Mayo 25, 1929, Fondo Alberto Salietti, Archivi del Museo del '900-Milano.

Benito Mussolini para Margherita Sarfatti, Rome, Julio 9, 1929, Fondo Margherita SarfattiArchivi del '900, MART-Rovereto.

Giovanni Rolleri para Alberto Salietti, Enero 31, 1929, Fondo Alberto Salietti, Archivi del Museo del '900-Milano.

Margherita Sarfatti para Mario Sironi, Mayo 28, 1930, Fondo Margherita Sarfatti- Archivio del '900- MART-Rovereto.

Margherita Sarfatti para Mario Sironi, Junio 5, 1930, Fondo Margherita Sarfatti- Archivio del '900- MART- Rovereto.

\title{
Notas
}

\begin{abstract}
* Laura Moure Cecchini is Lauro de Bosis Postdoctoral Fellow at Harvard University (2020) and Assistant Professor of Art History at Colgate University, where she teaches courses on the global avant-gardes and modernisms, with a special focus on fascist sculpture, painting, and architecture. She also studies the artistic and cultural exchanges between Italy and Latin America during the interwar period. Her work has appeared or is forthcoming in The Art Bulletin, Modernism/modernity, Italian Studies, and the International Yearbook of Futurist Studies, among other venues, and has been supported by the National Endowment for the Humanities, Harvard University, Trinity College, the Center for Italian Modern Art, and the Wolfsonian Collection. Email address: <Imourececchini@colgate.edu>. ORCID: <https://orcid.org/0000-0002-3755-9962>.

1 En aras de claridad, en este trabajo diferenciaré entre Sette Pittori del Novecento o Novecento milanese, un movimiento de siete pintores que fue lanzado por Margherita Sarfatti en 1922 y que concluyó hacia 1924, y Novecento italiano, presentado al público con la Prima Mostra d'Arte del Novecento Italiano en 1926.
\end{abstract}

Artigo recebido em outubro de 2019. Aprovado em dezembro de 2019. 